\title{
A REVIEW: GARBAGE COLLECTION MANAGEMENT SYSTEM
}

\author{
P.A. Lokhande ${ }^{1}$, M.D.Pawar ${ }^{2}$ \\ ${ }^{1} P G$ Research Student, Department of Electronic and Telecommunication Engineering, Maharashtra Institute of \\ Technology, Aurangabad (MS), India \\ ${ }^{2}$ Associate Professor, Department of Electronic and Telecommunication Engineering, Maharashtra Institute of \\ Technology, Aurangabad (MS), India
}

\begin{abstract}
Now a days, Garbage collection management is very important issue for cleaning the environment. Due to increasing population there is increase in garbage. This garbage contamination into an environment that causes a large irreversible effect, Absence of order, detriment or distress to the ecosystem. Especially developing countries as well as most populated cities are very badly affected by the population. Proper arrangement, categorization or classification of garbage is necessary to make environment clean, but improper disposal garbage cause to various issues like health problems, hazards, pollution. Garbage removal as well as management of removable garbage are performed the main role to improve the health of the people. For garbage collection management performed by manually in traditional way as well as by using modern technologies. Garbage management is performed by using various technical parts like sensors, Zigbee, GSM/GPRS, RFID, GPS and GIS.
\end{abstract}

Keywords: Sensors, Zigbee, GSM/GPRS, RFID, GPS, GIS

\section{INTRODUCTION}

With the increase the population and the process of the formation and growth of cities as well as industrial area also increases at same time to protect the environment and to make sure and secure clean and healthy globe. So there is need to collect the solid waste in proper manner and disposal in proper way. Management of garbage is very vital issue in over world [1]. There are different information and communication technologies like Radio Frequency Identification (RFID), Geographic Information System (GIS), Geographic Positioning System (GPS), various transportation model to apply bin monitoring as well as garbage collection [1,2].

In daily life, see the garbage bins situation which are overflowed and spread out garbage[3]. Because of this overflowed garbage generated harm full and toxic gases, disorder and ugliness. Avoid these problems, there is collection and proper management of garbage. The condition of being uninformed of cleanliness is spoiling our environment[4]. The main problem in garbage collection and management system is deficient information about the collecting time and area. When garbage from bins spilling out results in pollution. Pollution is contamination of hazardous chemicals into environment. This has great effect on health as well as hygiene of the people[5]. The main aim of this paper is to mainly focus on cleaning environment and reduce this issue from the roots.

\section{TRADITIONAL APPROACH}

The process of collecting the garbage bin in traditionally is such way that when cleaner is present near the dustbin and he noticed it that dustbin is filled with garbage and it is overflowed then he replaced it. But either he is not present at that place where the garbage bin or he did not notice then cleanliness is not keeping very well.

\section{Disadvantages}

1) Monitoring system is not properly work for cleaning purpose.

2) Information regarding the dustbin is not known to the cleaner at particular time then causes the spreading of garbage and generates the toxic gases as well as disorder.

\section{MODERN APPROACH}

In modern technique, there is smartly managing the process of collecting garbage. In that uses technological things like Sensors, GSM/GPRS, GPS, Zigbee, GIS, and RFID etc. These techniques are used for the long distance communication. When garbage bin is full the by using these technologies information related to garbage bin sent to the cleaner for cleaning purpose. Garbage bin is collected by the cleaner at particular time.

Md. Abdulla Al Mamun et.al proposed a system that consist a novel paradigm of solid garbage bin monitoring system by using a network of sensor which is wireless. When someone throws garbage insight the bins, sensor network can respond. The system uses zigbee technology as well as GSM/GPRS technology and for the monitoring purpose a set of sensors chosen with care. The system output showed immediately.

The system contains three sections such as lower, middle and upper. The lower section consist that part where sensors are attached to the dustbin which are used to measure the level of dustbin for filling with garbage, heaviness of garbage, condition of dustbin with respect to heat or cold and a moderate degree of wetness inside the bin. This lower 
section is used for to measure as well as transmit bin status to the next section through RF technology. The middle tier contains the gateway, which consist of zigbee as well as GSM/GPRS. Zigbee and GSM/GPRS modules that can receive the information from lower section where sensors are placed and forward it to the control station and control station is remain for a long time in upper section. Upper section that information is stores and examines for further use. In the upper section consist of main collection of the information as well as set of application programs for accumulating and observing purpose.

In the system the lower tier contains sensors which are used to transmit the information to gateway through Zigbee-PRO technology. The gateway contributes for creating contact between the zigbee in the lower section and GSM in the upper section. The gateway is used to reduce a distance between the sensor node in the lower section and the servers in the upper section. For the information receiving purpose XBee-ZB-PRO RF transceivers module is used in the gateway and sim900 GSM/GPRS module is used to provide long distance communication.

The information is received by gateway from the sensor node then it send to the control area. It consists with database server as well as web server. Web browser is used to monitor the bin status by user. ISM bands use in lower tier for shunning supplementary cost of telephone operator subscription as well as by allow lower power transmission. In that middle section uses GSM/GPRS technology which almost available everywhere while supports large distance communication to remote observing. The upper section contains control station which store the information can be used further in application like analyzing programs, organizing, routing algorithm.

In this way the system can be help to reduce cost of operation and the collected information support system.

Md Shafiqul Islam et.al introduced a system combined of Radio Frequency Identification(RFID), Global Position System (GPS), General Packet Radio Service (GPRS), Geographic Information System (GIS) and web camera. In the developing countries, garbage monitoring as well as management become an acute problem for their process of the formation and growth of cities and pertaining to the study of money and its movement. Wastes generated from the industrial as well as domestic activities and have a negative impact on environmental globe. There is necessary a proper disposal of garbage.

In a system hardware is consisting RFID tag and RFID receiver. The main role of RFID gives priority towards to build up wireless network for garbage bin assembling as well as monitoring. RFID technology is very important for the reuse by using reverse supply chain. RFID system is managed $20 \%$ garbage collection. RFID is recent technology as well as receiving large amount of attention. The RFID reader in trucks would automatically get back all information of patron and RFID tag gives garbage bin information which attached with each bin. GPS will give the information about location of truck, which collects bins. In a system GPRS communication is used. All the information of the control server would up-dated without any external interference by using GPRS. GIS map server is used for truck observing or noticing purpose. The information related to the bin and truck has been developed in the way that bin and truck identification, date and time period is required for collection of garbage, coordination information about garbage bin and vehicle GPS and stored this information for observing as well as managing purpose. The results displayed on real-time image processing, histogram analysis and other information which is related to garbage bin have been displayed in the GUI of noticing system.

From the performance of the system have been examined as well as focused that it has high speed for sending and receiving process, results are instantly showed for communication purpose.

Kanchan Mahajan et.al described a system in that there are zigbee and GSM technologies are used. The combination of these two technologies is latest trend. Zigbee uses the 2.4 $\mathrm{GHz}$ frequency to deliver a various type of information and easy to use anywhere in the required location. Zigbee is used for sending and receiving information over long distance. Zigbee consist of a lesser data rate, longer battery life and secure networking. Sensors are used in system, which are attached to the garbage bin. This garbage placed at the public area.

The sensor is placed at the lead position of dustbin. When dustbin filled by garbage, garbage reaches up to the level where sensors are attached, notification will be given to the controller through Zigbee. Zigbee present at the receiver side will receive that command as well will display on Liquid Crystal Display (LCD) and computer control station. Here ARM7 controller is used. The controller will give the indication to a driver of vehicle who collect garbage as to dustbin is completely filled as well as needs to notice. In a system GSM is used for the sending the SMS to the driver through ARM7 microcontroller.

The system can help to collect the solid waste in time, minimum route and low fuel use, clean and healthy environment.

Pavithra developed a system consist of IR and gas sensor. This IR sensor is placed inside the dustbin sense the level of trash as well as gas sensor will sense the toxic gas inside the trash bin. Sensors are used for the sensing and communication. IR sensor used for to measure the speed of moving object in industry. When trash is filled then RFID which placed at trash gives information to the corporation office. RFID in corporation is serial interface with PC.

In that system VB code is used. The information is related to the trash and also about the location of trash is sent to truck driver. If the trash is not replaced by truck driver then microcontroller which is place at the trash is sent the 
information to the corporation office one more time. The information about trash is continuously displayed on LCD in corporation office up to the trash is not replaced. The trash is filled then alarm is ringing. When trash is removed then alarm stops.

Priya B.K. et.al described that a system consist of two unit's like transmitter unit and receiver unit. In transmitter unit consist of three sensors like infrared sensor, moisture sensor and gas sensor. These sensors are connected to the garbage bin which is placed at the public place. The infrared sensor is used to sense the garbage in dustbin either it reaches at level of sensor or not. This level sensor is gives the indication to microcontroller.

Here used PIC16F877A microcontroller that the dustbin is needed a attention to empty it by the cleaner. Moisture is sense the moist in dustbin when someone throw wet garbage in dustbin and third sensor is gas sensor is sense the unpleasant smell and toxic gases are generated in dustbin. These sensors are sent this information to the microcontroller. In transmission unit the microcontroller receives all information related to the garbage bin and sends the data using encoder as well as radio frequency (RF) transceiver.

In receiver unit by using radio frequency receiver all data is received and these data are decoded by using decoder. The decoder will send garbage information to microcontroller using radio frequency (RF) transceiver that present on receiver unit. All the information will be displayed on the LCD indicating the garbage bin number which needs argent attention by the cleaner. Type of waste deposited in garbage bin is depends on sensors.

Sauro Longhi et.al introduced a system in that garbage management is complex process it consist of many steps like generation, transfer from one place to another place, collection and disposal of garbage. In a system on-site handling, storage, disposal processes aretopics that focused. Improved the efficiency of garbage on-site collection as well as transfer. There is innovative solution for monitor and management of the garbage bin. For garbage bin monitoring purpose, there is Wireless Sensor Network (WSN) has been developed.

In a system sensor section performs data receiving and data sending function. The information is sent to a supervisor system. A wireless sensor network consist of sensors which are monitor the parameter of garbage bin like degree of bin, wetness due to wet garbage, etc. and exchange their information through the area of sensor network. A sensor network has sensing components.

The architecture consist of three parts namely Long range communication modules, Server layer, User interface. In long range communication module contain Quectel M10 GSM/GPRS technology. It provides flexibility as well as reliable cost. Second part is server layer, is perform the role between user as well as WSNs. Last part is user interface that allows a user to interact with the whole system.

Maher Arebey et.al explained integrated technologies like Radio frequency identification, Global Position system, GSM/GPRS, Geographic Information System. RFID is vast technology is designed reader capture the data on tag as well as sending it to the system by using wireless connection. Another technology is self-identification technology is used to reduce the time and accuracy of data.

GPS is related to the satellite. The satellite is emits the radio signal to GPS receiver. GPS receiver is used to calculate distance in two-dimensional as well as three dimensional positions.

GPRS is joined with internet. It provides a connection between mobile operator as well as information network. GPRS is used wireless channel for data transfer rate is 160 Kbps. GPRS is used in large distance for information sending and receiving purpose in real time.

GIS is used for collection, managing data and showing all the results in geometrical information in a computer system.

\section{CONCLUSIONS}

In Garbage collection process is performed by smart way. In that previously is carried out by a simple way, when garbage bin is filled with trash then cleaner is seen the position of garbage bin then collect. But when cleaner is not present that position of garbage and dustbin is overflowed and disorder is spread in area. It is very bad Scene. In smart way garbage collection and management process is performed by using wireless technology network like Zigbee, GPS, GIS, GSM/GPRS technology. Zigbee is used for long distance communication for sending the data related to the dustbin. GSM is used for the sending short message service to cleaner to clean the dustbin. Not necessary cleaner is present every time near to dustbin to collect it. When dustbin is filled then by using GSM, SMS sent to cleaner. Garbage level sensing process is performed by the level sensor, some moist is generated in dustbin due to the wet garbage thrown into dustbin is sensed by the moisture sensor and toxic gases are generated in dustbin is detect by using gas sensor. By using these technologies keep the environment clean and healthy.

\section{REFERENCES}

[1]. Md. Abdulla Al Mamun, Hannan, Aini Hussain, Hassan Basri, "Wireless sensor Network Prototype for solid Waste Bin Monitoring with Energy Efficient Sensing Algorithm", $16^{\text {th }}$ international conference on computational Science and engineering, December 2013.

[2]. Md. Shafique Islam, M.A. Hannan, "An overview for Solid Waste Bin Monitoring System”, Journal of Applied Science Research, February 2012.

[3]. Kanchan Mahajan, Prof.J.S.Chitode," Waste Bin monitoring system using Integrated Technology", 
International Journal of Innovative Research in Science engineering and Technology, July 2014.

[4]. Pavithra, "Smart trash system: An application using Zigbee", International and Technology, October 2014.

[5]. Priya B.K., T.Lavanya, V. samyakta Reddy, "Bin That Think's", International Journal of Science and Technology, June 2015.

[6]. S. Longhi, Gianluca Di Buo, Mario Prist ,"Poster abstract: A wireless sensor network architecture for solid waste management", ResearchGate, February 2012.

[7]. Maher Arebey, M. A. Hannan, Hasaan Basri, R. A. Begum, Huda Abdullah, "RFID and Integrated Technologies for Solid Waste Bin Monitoring System", Proceeding of the world congress on engineering, July 2010 . 